Revista de Economia Política, vol. 34, no 1 (134), pp. 39-60, janeiro-março/2014

\title{
Estado, bloco no poder e acumulação capitalista: uma abordagem teórica
}

\section{EDUARDO COSTA PINTO PAULO BALANCO*}

State, power block and capitalist accumulation: a theoretical approach. This article aims to elaborate a theory, based on Poulantzas, about the role of the State in a capitalist economy through a relational perspective that perceives the State as a field and a strategic process for the disputes of class fractions within the power bloc. In order to do so, it exposes the relation between State and accumulation at an abstract-formal level, emphasising the limitations of studies that use only this dimension. Next, it analyzes the role of the power bloc in mediating between the abstract and concrete levels of the State, observing that public policies are elaborated as a result of the clashes within the power bloc. Finally, it promotes a discussion on the external constraints (international system) that are affected and affect the State and, consequently, the dynamics of the power bloc.

Keywords: State; power bloc; capitalist accumulation.

JEL Classification: P10; P16.

\section{INTRODUÇÃO}

Estudos contemporâneos, dos mais diversos matizes teóricos, concebem o Estado, quase sempre, como um criador autônomo e idealizado que determina a sociedade e suas estruturas (alçando-o à condição de fonte primária do processo reprodutivo) ou como uma criatura passiva que é o reflexo da sociedade

\footnotetext{
* Respectivamente, Professor adjunto do Instituto de Economia (IE) da UFRJ. E-mail: eduardo.pinto@ ie.ufrj.br; Professor do Curso de Mestrado em Economia da Universidade Federal da Bahia, E-mail: balanco@ufba.br. Este artigo é uma versão ampliada das subseções 1.3 e 1.4 da tese de doutorado denominada "Bloco no Poder e Governo Lula", defendida no Instituto de Economia da UFRJ em 2010 - Pinto (2010) - e orientada pelo professor Reinaldo Gonçalves. Agradecemos a Mauro Santos Silva e a Ronaldo Fiani pelas críticas e sugestões, assumindo a versão final como de nossa exclusiva responsabilidade. Submetido: 5/dezembro/2012; Aprovado: 13/março/2013.
} 
(reduzindo-o à condição de um comitê da burguesia ou de uma arena neutra que apenas reflete o mercado eleitoral). Ao adotarem tais suposições, esses estudos esvaziam a dimensão da política no nível concreto-real (ou da conjuntura), uma vez que deixam de lado a análise dos condicionantes internos ao Estado (sua ossatura e as suas disputas internas - locus político onde se travam os embates entre os segmentos dominantes e os populares) que são fundamentais para compreender a construção e a adoção de medidas estatais, em especial a política econômica.

Por conseguinte, este artigo visa apresentar uma teorização acerca do papel do Estado na economia capitalista por meio da perspectiva relacional que compreende o Estado como um campo e um processo estratégicos onde se entrecruzam núcleos e redes de poder das frações de classe do bloco no poder; para essa finalidade, toma-se como referência a abordagem desenvolvida nos últimos trabalhos de Poulantzas. Este conceito, bloco no poder, será utilizado com a finalidade de realizar a mediação entre as dimensões abstrato-formal ${ }^{1}$ e concreto-real do Estado quando atuam como mecanismo unificador entre a acumulação (capital em geral) e as frações de classe (pluralidade de capitais).

Além desta introdução, descreve-se, na segunda seção deste artigo, de forma sintética, a relação entre o Estado e a acumulação no plano abstrato-formal (do capital em geral), destacando que as análises do Estado (estruturalistas, classistas e derivacionistas), que são realizadas apenas nesse plano analítico, não conseguem apreender a conjuntura dos conflitos políticos que são travados no interior do Estado. Na terceira seção busca-se analisar o papel desempenhado pelo bloco no poder na mediação entre os níveis abstrato e concreto do Estado, ressaltando os mecanismos e conflitos internos que influenciam a gestão das políticas públicas. $\mathrm{Na}$ quarta seção procura-se analisar como o bloco no poder, por meio do Estado, consegue projetar seu poder de classe no sistema internacional, dado o grau de soberania que este mesmo Estado desfruta diante de outras nações. Por fim, na quinta seção, alinhavam-se alguns comentários a título de conclusão.

\section{ESTADO E ACUMULAÇÃO: PLANO ANALÍTICO ABSTRATO-FORMAL (A ANÁLISE DO CAPITAL EM GERAL)}

O conflito entre capital e Estado no modo de produção capitalista (MPC)² é

\footnotetext{
${ }^{1} \mathrm{O}$ objeto abstrato-formal corresponde a um recurso metodológico utilizado no âmbito do processo de produção do conhecimento. Embora não exista na realidade, contudo, pode ser empregado para fins operacionais na construção de um modelo voltado para a interpretação da realidade. $\mathrm{O}$ existente, a verdadeira dimensão a ser apreendida, é um objeto concreto-real determinado histórica e geograficamente.

${ }^{2} \mathrm{O}$ modo de produção representa uma combinação de diversas estruturas e práticas que compreende diversos níveis, tais como o econômico, o político e o ideológico, com dominância, em última instância, do econômico. Esse todo complexo representa um esquema indicativo, que pode ser operado, em termos analíticos, por meio de uma divisão mais exaustiva. Em outras palavras, é um objeto abstrato-formal que serve como fins operativos para a construção de um modelo que pode ser utilizado para interpretar a realidade (Poulantzas, 1977). Na verdade, o que existe é uma formação social (FS) historicamente determinada que é "um todo social - no sentido mais vasto - em um dado momento de sua
} 
perceptível somente quando se considera os capitalistas individualmente (frações de classe), em suas disputas e em suas relações com o Estado num determinado contexto histórico e espacial (plano concreto real/nível conjuntural), uma vez que na dimensão do capital em geral (plano abstrato-formal) ocorre uma dialética "virtuosa e feliz". Nesse plano, o Estado "é a 'forma política' da sociedade burguesa" em que "o 'poder de Estado' identifica-se plenamente com o poder de classe", já que a autonomia que o Estado adquire "em determinadas situações históricas não faz dele uma força social 'autônoma' ou 'descolada' da sociedade" (Codato \& Perissinoto, 2001, p. 17).

Em uma das primeiras grandes obras de relevo de Marx e Engels, o Manifesto comunista (1848, p. 3), já podemos localizar uma referência à igualdade entre poder de classe e poder de Estado; trata-se da notória passagem em que afirmam que "o executivo no Estado moderno não é senão um comitê para gerir os negócios comuns de toda a classe burguesa". Isto quer dizer que o Estado, embora contrarie às vezes os interesses imediatos dos capitalistas individuais, atua em prol, no longo prazo, dos capitalistas como coletividade. O problema, segundo Poulantzas (1985), é que certo marxismo (particularmente, os integrantes da II e da III Internacionais) incorporou apenas esta perspectiva isoladamente, deixando de lado obras políticas/ históricas de Marx, tais como O 18 brumário de Luis Bonaparte e As lutas de classe na França de 1848 a 1850, sem perceber que essa é uma dimensão mais abstrata do Estado e, por essa razão, mais recomendada para uma análise do capital em geral. Ao adotar tal caminho, reduziu o Estado a uma dominação política (Estado-poder) em que cada classe (ou fração) dominante seria capaz de formatar sua própria configuração de Estado a partir de suas conveniências e interesses. Porém, diz respeito a uma concepção puramente instrumental em que todo Estado, em qualquer plano analítico, seria sempre uma ditadura de classe, tornando-se um apêndice da base estrutural. Logo, a partir dessa conclusão, não faria nenhum sentido pensar uma teoria de Estado.

Todavia, é preciso observar que não se quer aqui negar a importância analítica da relação entre Estado e capital em geral, sobretudo para compreender o processo de acumulação, mas sim mostrar que essa dimensão analítica por si só não permite compreender o Estado como o locus político em que se manifestam as lutas políticas das frações das classes dominantes, bem como as dos segmentos populares.

Voltemos ao papel do Estado no plano abstrato-formal: na verdade, ele funciona como o grande organizador tanto da acumulação como da ordem capitalista na medida em que atua na construção de elementos institucionais e econômicos favoráveis à acumulação do capital. De modo geral, os principais instrumentos de atuação do Estado estão assentados, a saber, no (i) monopólio do uso da violência para garantir e proteger a propriedade privada; na (ii) formulação e imposição das

existência histórica: a França de Luís Bonaparte, a Inglaterra da Revolução Industrial” (Poulantzas, 1977, pp. 14-5). 
leis (destacadamente as referentes à gestão estatal da força de trabalho) que criam os instrumentos legais para o cumprimento dos contratos e regulam a forma de trabalho por meio da disciplina do trabalho e da insegurança do emprego; e na (iii) gestão da moeda, da tributação e da dívida pública (políticas monetárias e fiscais) que garantam a estabilidade do valor real da moeda, a regulação do conflito distributivo e assegure a previsibilidade para a rentabilidade (ou cálculo empresarial privado etc.) (Brunhoff, 1985; Panitch \& Gindin, 2005; Cardoso Jr., Pinto \& Tarso, 2010).

A dialética virtuosa entre Estado e capital, nesse plano analítico, assumiu diferentes formas ao longo das diversas fases do capitalismo. Na fase da acumulação originária, o importante período pré-capitalista entre os séculos XV e XVIII, o Estado absolutista europeu recorreu a formas de violência extraeconômica com o propósito de abrir espaços para a afirmação do capitalismo por meio da expropriação e expulsão de parte do povo do campo. Desta maneira, criou as condições tanto para transformar "os pequenos camponeses em trabalhadores assalariados, e seus meios de subsistência e de trabalho em elementos materiais do capital" como para criar "ao mesmo tempo, para esse último [o capital] seu mercado interno", separando radicalmente os produtores campesinos dos seus meios de produção (Marx, 1867, p. 283).

Com o avanço da separação entre o político e o econômico ${ }^{3}$ no MPC, o Estado, de maneira geral, sobretudo nos países onde as forças produtivas mais avançaram, reduziu sua participação direta na organização da produção, na realização do investimento e na apropriação do excedente. No entanto, manteve-se ativo para garantir a ordem jurídica, a regulamentação da infraestrutura, a regulação das relações capital-trabalho, bem como para gerir a macroeconomia e atuar como emprestador de última instância (Panitch \& Gindin, 2005).

Nesse sentido, o capitalismo não existiria sem o Estado, já que equivale a uma instituição intrínseca e indissociável da própria sociedade e do seu movimento histórico (bloco no poder, lutas de classes etc.). Com isso, as formas de atuação do Estado e de sua estrutura organizacional (ossatura e seus núcleos de poder) não devem ser entendidas como um simples reflexo passivo da sociedade autorregulada pelos mercados; ${ }^{4}$ muito menos deve ser visto como um elemento autônomo/exógeno idealizado que determina a sociedade como uma fonte primária do processo repro-

\footnotetext{
${ }^{3}$ Para Poulantzas (1985), essa separação fora fruto da divisão entre trabalho manual e intelectual, da individualização do direito e da nação no modo de produção capitalista, já que o processo produtivo, sob o capitalismo, separa e individualiza os trabalhadores, ao mesmo tempo em que o Estado os reintegram no povo-nação, obrigando-os a se submeterem a um conjunto de instituições que os homogeneízam e que, ao mesmo tempo, os diferenciam por meio de uma série de leis, valores, normas, tradições e línguas.

${ }^{4}$ Numa perspectiva liberal, o sistema político seria um mercado, no qual as decisões dos eleitores seriam baseadas em suas utilidades políticas, já que o Estado seria neutro/passivo - o reflexo do mercado econômico e eleitoral e, por conseguinte, dos seus intercâmbios impessoais, competitivos e livres - e um servidor do eleitorado.
} 
dutivo. Esta suposta dicotomia teórico-analítica da compreensão do Estado é fruto da separação problemática (tanto na forma como em conteúdo) entre sociedade civil $^{5}$ - numa perspectiva liberal - e o Estado, que se mantém viva até hoje.

Vale ressaltar ainda que o papel do Estado diante da sociedade, mesmo no nível analítico do capital em geral (abstrato-formal), não pode ser nem um pressuposto (papel de criador autônomo acima das lutas de classes - perspectiva estruturalista - ou de criatura passiva que apenas reflete o poder das classes dominantes - ótica instrumentalista) nem uma derivação (escola da derivação lógico-histórica), pois a questão do Estado "é uma tarefa histórica, concreta, que se põe de diferentes maneiras para cada formação social”. Ao se adotar o caminho do pressuposto ou da derivação do Estado, no nível estrutural, estar-se-ia "antecipando os resultados dos processos políticos concretos", bem como prestando pouca atenção nos "acontecimentos históricos específicos, o que acabaria por dispensar-nos da própria pesquisa de orientação materialista." (Codato \& Perissinoto, 2001, p. 17).

O debate a respeito do papel do Estado realizado por boa parte do marxismo foi assumindo duas tendências diferenciadas: uma ótica instrumentalista (funcionalista) e outra estruturalista, ambas derivadas de uma ampla gama de posições. $\mathrm{Na}$ perspectiva instrumentalista o Estado funciona como um "instrumento nas mãos das classes dominantes, ou, mais concretamente, de suas variadas frações burguesas". Por outro lado, na ótica estruturalista, o Estado é concebido "como nada mais do que algo postado acima dos conflitos de classes, ou como instância dotada de total autonomia diante deles" (Oliveira, 2004, p. 216).

A discussão teórica desses dois eixos se renovou, ao longo dos anos 1970 e início dos 1980, a partir do debate analítico entre a visão estruturalista e a perspectiva da luta de classes, configurado por meio do debate entre Poulantzas (estruturalista) ${ }^{6}$ e Miliband (luta de classes). ${ }^{7}$ Para Poulantzas (1977), o Estado teria a função de coerção social e corresponderia aos interesses políticos da classe dominante. Entretanto, para ele, o Estado tem uma autonomia relativa no que tange às classes e frações de classe do bloco de poder. Noutra perspectiva, Miliband (1970) considera uma fraqueza a ideia de Poulantzas de autonomia relativa, pois considera que o MPC apresenta um “superdeterminismo estrutural”. Já Bonefeld

\footnotetext{
${ }^{5} \mathrm{O}$ termo sociedade civil utilizado nesta passagem está associado a uma perspectiva liberal tanto no campo econômico (Adam Smith, entre outros) quanto político (Rousseau, entre outros). Isto quer dizer que a sociedade civil seria fruto ou uma decorrência do direito de propriedade cuja sua afirmação seria o pressuposto da liberdade que só seria alcançada pela democratização do acesso a propriedade por meio de um pacto entre cidadãos e Estado.

${ }^{6}$ Nesta fase os escritos de Poulantzas tinham forte viés estruturalista - sob influência althusseriana -,
pois a luta de classe ocupava papel secundário diante das estruturas do Estado. Numa segunda fase (em
suas últimas obras), Poulantzas passou a atribuir maior importância ao papel das lutas de classes para
a configuração das estruturas do Estado, distanciando-se assim de Althusser e aproximando-se de
Gramsci.
${ }^{7}$ Para uma resenha detalhada do debate entre Poulantzas e Miliband ver Mollo (2001) e Carnoy (1986).
} 
(1987) afirma que as estruturas, entre elas o Estado, devem ser entendidas por meio do antagonismo entre capital e trabalho, ou seja, como resultado das lutas.

Para Mollo (2001, p. 357), as análises estruturalista, de Poulantzas, e classista, de Miliband, são insatisfatórias, uma vez que a apreciação tanto “da estrutura da relação entre Estado e sociedade civil, quanto à análise das lutas de classes precisam ser desenvolvidas como aspectos de um mesmo processo unitário". Isto não ocorre nessas duas perspectivas haja vista que seus focos se concentram na "existência ou ausência de poder de classe para alterar a estrutura”. A explicação dessas duas dimensões pela via unitária só poderia ser realizada, segundo Mollo (2001), a partir das leis de movimento do capitalismo (ou do capital em geral), conforme realizado pela visão "derivacionista” do Estado.

Então, para esta escola, que tem em Hirsch um de seus principais representantes, a lógica do Estado é determinada pela lógica do capital em geral por meio das leis objetivas do desenvolvimento capitalista. Em outras palavras, a análise da mediação entre a sociedade e o Estado deve ser efetivada a partir da derivação da forma Estado como decorrência das contradições da sociedade capitalista. Contradição esta materializada, para Hirsch, na tendência decrescente da taxa de lucro. Outros derivacionistas adotam outros elementos de contradição, contudo todos se baseiam nas leis objetivas do desenvolvimento capitalista. Assim, o Estado teria nascido (derivação lógico-histórica) para neutralizar essa tendência, segundo Hirsch, por meio dos gastos em infraestrutura física e financeira e em recursos humanos que funcionariam como contratendências (Carnoy, 1986; Mollo, 2001).

As perspectivas estruturalista e instrumentalista/funcionalista concebem o Estado, respectivamente, como criador e criatura. Ao adotarem tal caminho, o Estado é alçado ao status de fonte original do processo reprodutivo ou é reduzido a um comitê da burguesia. Tanto uma como outra perspectiva esvazia quase que por completo a dimensão da política no nível concreto-real (ou da conjuntura), pois eliminam a possibilidade de o Estado atuar como o locus político em que se realizam os embates entre as frações das classes dominantes e também entre as classes dominantes e os segmentos populares, bem como onde se configura a hegemonia de uma das frações dominantes.

No que diz respeito à ótica “derivacionista” do Estado, a questão da política (lutas das frações de classes) no nível concreto-real é praticamente eliminada, pois o espaço político do Estado e o poder capitalista são derivados exclusivamente das relações de produção (categorias econômicas do capital em geral), configurando-se como um determinismo economicista. Para Poulantzas (1985, p. 58), “essa problemática recai numa concepção assaz tradicional do capital como entidade abstrata com lógica intrínseca - as categorias econômicas -, e culmina em linhas de pesquisa insuficientes para explicar a especificidade material desse Estado".

Nesse sentido, a suposição do Estado criador ou criatura, ou a derivação do Estado, praticamente eliminam a questão da política, já que essas visões se negam a prestar atenção aos acontecimentos históricos específicos, ao mesmo tempo em que antecipam os resultados do processo político por meio da exclusiva análise abstrato-formal. Logo, depreende-se que a compreensão do papel do Estado na acumulação 
e reprodução do capitalismo não pode ficar restrita apenas à acumulação do capital em geral (nível maior de abstração ou objeto abstrato-formal), mas sim também deve incorporar a percepção das maneiras como as frações e as classes (em suas lutas políticas) exercem seu poder na busca pela manutenção ou ampliação da sua fatia da renda e da riqueza e de sua legitimação por meio da influência exercida nos aparelhos do Estado e, por conseguinte, da proposição das políticas públicas.

Portanto, é preciso compreender a forma de dominação no locus da luta política de classe (Estado), que vai muito além da perspectiva binária entre os segmentos dominantes e dominados, já que uma formação social implica a existência de várias classes e frações de classe que estão em constante luta. Para tanto, faz-se necessário utilizar o objeto (concreto-real) bloco no poder para tentar iluminar a especificidade material do Estado que é dada pelas especificidades históricas das lutas políticas das frações das classes dominantes.

Assim, tenta-se aqui buscar a conexão entre a dimensão concreto-real e abstrato-formal do Estado por meio da utilização do conceito de bloco no poder, procurando resgatar a dimensão materialista histórica da pesquisa na medida em que se eliminam resultados determinados a priori como os observados pelos que utilizam apenas a dimensão do capital em geral.

\section{ESTADO E BLOCO NO PODER: PLANO ANALÍTICO CONCRETO-REAL (UNIDADE CONTRADITÓRIA DA LUTA DE CLASSES)}

Antes de avançarmos, faz-se necessário explicar a noção do bloco no poder: denominamos este, preliminarmente, como a expressão de uma configuração histórica das relações entre as classes dominantes em seus desenlaces no Estado capitalista (unidade política específica - objeto concreto-real). Este complexo de relações denota uma especificidade, própria do Estado capitalista, a qual, segundo Poulantzas (1977, p. 224, grifo do autor), se constitui como

[...] a relação entre, por um lado, um jogo institucional particular inscrito na estrutura do Estado capitalista, jogo que funciona no sentido de uma unidade especificamente política do poder de Estado, e, por outro lado, uma configuração particular das relações entre classes dominantes: essas relações, na sua relação com o Estado, funcionam no seio de uma unidade política específica recoberta pelo conceito do bloco no poder.

Poulantzas (1977), apoiando-se em alguns textos políticos de Marx (1852 e 1850), afirma que o bloco no poder pode ser explicitado por meio de três elementos, a saber:

1. Pelo conjunto de determinadas instituições - datadas historicamente - do Estado capitalista em sua relação com a luta política de classe. Aqui o Estado deve ser compreendido em sentido ampliado, segundo os termos gramscinianos (sociedade política + sociedade civil). O sufrágio universal, 
como uma das instituições do Estado capitalista, pode ser utilizado para exemplificar tal situação, a saber, o sufrágio, no contexto de um Estado capitalista, constitui-se num alargamento das relações entre o Estado e a coexistência de várias classes ou frações de classes dominantes;

2. Pelo campo das práticas políticas das classes e frações dominantes numa determinada conjuntura capitalista. Em outras palavras, o bloco no poder depende da pluralidade das classes ou frações dominantes numa dada formação histórica. Tal condição está associada à definição das frações de classes dominantes que necessariamente apresentam determinada autonomia, a qual, por sua vez, depende de elementos de coesão político-ideológicos e econômicos numa determinada conjuntura histórica e espacial.

3. Pela divisão da classe burguesa em frações no interior do modo de produção capitalista. Frações (comercial, industrial e financeira) estas que não se relacionam simplificadamente com os efeitos particulares de instância política. Nesse sentido, inclusive, há determinadas circunstâncias em que as consequências da instância política podem gerar frações de classe apenas no campo da prática política de classes.

A partir destes três constatações, Poulantzas (1977) assim definiu o bloco no poder: uma unidade contraditória entre distintas classes e/ou frações de classes, sob a hegemonia no seu interior de uma dessas frações ou classes, em suas relações com o Estado capitalista. Sendo assim, o conceito de bloco no poder está arrolado ao nível político na medida em que recobre o campo das práticas políticas de classe, refletindo o conjunto das instâncias, das mediações e dos níveis da luta de classes numa determinada conjuntura histórica de uma formação social. Com isso, no nível concreto-real, o bloco no poder acaba assumindo uma função equivalente ao conceito de forma de Estado. É preciso destacar ainda que a hegemonia restrita de uma das frações no interior do bloco no poder é dada pela capacidade desta em liderar os interesses econômicos, políticos e ideológicos das demais frações e classes do bloco. Quando essa hegemonia alcança o conjunto da sociedade (abarcando dominantes e dominados) ela deixa de ser restrita e passa a ser ampla. ${ }^{8}$

\footnotetext{
${ }^{8}$ Cabe uma rápida digressão sobre o conceito de hegemonia ampla utilizada ao longo deste artigo. Este termo equivale ao mesmo termo hegemonia utilizado por Gramsci (1949). Logo, a hegemonia ampla ocorre quando a classe dominante, ou uma de suas frações, ocupa um lugar decisivo no padrão de acumulação num determinado momento histórico e, a partir de seus interesses econômicos, políticos e ideológicos, consegue uma unidade orgânica ("bloco histórico") entre as demais frações das classes dominantes, de forma consentida, articulando, ao mesmo tempo, seus interesses aos das classes dominadas. Dado que o conceito de hegemonia de Gramsci é igual ao conceito de hegemonia ampla, qual seria então o sentido de utilizar este novo termo em vez do utilizado? Na verdade, isso se deve ao fato de que a hegemonia pode ficar restrita apenas ao âmbito das frações dominantes. Situação esta que Gramsci não contemplou em sua acepção, já que para ele a "sociedade política" (Estado) tinha um caráter fundamentalmente de coerção, ao passo que este conceito só caberia à "sociedade civil" (Poulantzas, 1977). Contemporaneamente, não é mais factível pensar na "sociedade política" (Estado) apenas na dimensão da coerção política como houvera apresentado Gramsci. Poulantzas (1977), dentre outros, mostrou a necessidade da incorporação da hegemonia aos estudos sobre a "sociedade política"
} 
Vale ainda ressaltar que a unificação, por meio do bloco no poder, não elimina seu caráter conflituoso, já que "a luta de classe, a rivalidade dos interesses entre as frações sociais, encontra-se nele constantemente presente, conservando esses interesses a sua especificidade antagônica [...]" (Poulantzas, 1977, p. 233, grifo do autor). Neste contexto, a hegemonia restrita de uma classe ou fração não surge ao acaso, mas sim é possível

[...] através da unidade própria de poder institucionalizado do Estado capitalista. [...]. A classe ou fração hegemônica polariza os interesses contraditórios específicos das diversas classes ou frações no bloco no poder, constituindo os seus interesses econômicos em interesses políticos, representando o interesse geral comum das classes ou frações do bloco no poder: interesse geral que consiste na exploração econômica e na dominação política [...]. O processo de constituição da hegemonia de uma classe ou fração difere quando essa hegemonia se exerce sobre as outras classes e frações dominantes - bloco no poder -, ou sobre o conjunto de uma formação, inclusive sobre as classes dominadas [...] (Poulantzas, 1977, pp. 233-234)

O bloco no poder, na verdade, é formado pelas classes (e frações) que ocupam o locus da dominação da luta política de classes, ou seja, que possuem áreas de poder próprias (centro de poder $=$ poder real) no seio do aparelho de Estado. Mesmo assim, é preciso deixar claro que o bloco no poder não significa o conjunto de camadas que apoiam (classes-apoios ${ }^{9}$ ) o poder de Estado, mas sim os que participam do espaço de dominação política. De maneira geral, a fração ou classe dominante que exerce a hegemonia restrita ao bloco no poder também é a que assume

(Estado). Apesar disso, ele utilizou o termo hegemonia indistintamente tanto para analisar a sociedade política, mais especificamente o bloco no poder, quanto para analisar as frações fora do bloco no poder. Para este artigo, julgou-se ser mais conveniente diferenciar estas dimensões. Para tanto, denominar-se-á de hegemonia restrita (ao bloco no poder) a situação em que a hegemonia de uma fração fica restrita ao bloco no poder dominante, ao passo que a hegemonia ampla significa uma situação em que uma fração do bloco no poder consolida unidade orgânica entre dominantes e dominados (bloco histórico).

${ }^{9}$ As classes-apoios são as frações ou classes que, apesar de fazerem parte dos segmentos dominados, apoiam, em determinada conjuntura histórica, uma forma do Estado capitalista, tais como os camponeses parcelares e o lumpemproletariado proletariado no contexto do Estado bonapartista francês e a pequena burguesia no fim do primeiro período da república parlamentar, também na França. Os dois principais elementos que podem explicar os fatores que levam essas classes dominadas a sustentarem o bloco no poder são: 1) o processo de ilusões ideológicas, já “[...] que o apoio a uma dominação de classe determinada não é em geral baseado em qualquer sacrifício político real dos interesses do bloco no poder". No entanto, “esse apoio, é indispensável a essa dominação de classe [...]” (Poulantzas, 1977, p. 238). Caso típico: o lumpemproletariado na França de Luís Bonaparte; 2) o temor, fundado ou imaginário, do poder das classes operárias. "Neste caso, o apoio não se encontra baseado, seguramente, em uma comunidade de interesses a partir de sacrifícios mútuos reais, nem em uma ilusão ideológica relativa a este sacrifício, mas sobre o fator político da luta da classe operária [...]. Caso típico: o estatuto, em certas conjunturas, da pequena burguesia" (Poulantzas, 1977, p. 239). 
a hegemonia ampla com relação ao conjunto da sociedade ${ }^{10}$. No entanto, a regra geral da dupla função de hegemonia (ampla e restrita) de uma determinada fração dominante depende da conjuntura das forças sociais. Com isso, existe a "[...] possibilidade de defasagem, de dissociação e de deslocamento dessas funções de hegemonia em classes ou frações diferentes [...], que tem consequências capitais ao nível político" (Poulantzas, 1977, p. 235).

Nesse sentido, o bloco no poder, bem como sua dinâmica e periodização histórica, é conformado na dimensão das práticas políticas de classe que é diferente da cena política, já que esta última se circunscreve ao campo dos partidos políticos. A despeito das diferenças entre prática e cena política, esses elementos, em determinadas conjunturas históricas e espaciais, podem se interpenetrar causando uma falsa ideia de que prática e cena constituem uma unidade indissociável - situações históricas em que boa parte das classes ou frações está representadas por partidos políticos no sistema representativo. Inclusive, segundo Poulantzas (1977, p. 246), uma situação como essa gera em boa parte da ciência política contemporânea uma dupla confusão quando "reduz as relações de classe às relações entre partidos, e as relações entre partidos às relações de classe". Isso limita a análise das formações sociais (datada historicamente e determinada espacialmente) na medida em que não indica os limites e as defasagens entre as práticas políticas de classe - ações do bloco no poder - e a cena política - representação dos partidos políticos numa dada forma de regime.

O próprio Marx (1850 e 1852) afirmou que a introdução do sufrágio universal induziu as classes dominantes a assumirem um papel ativo na cena político-eleitoral mediante a organização de partidos políticos. No entanto, Poulantzas (1977), bem como Marx (1850 e 1852), afirmaram que em determinadas conjunturas histórico-espaciais podem ocorrer defasagens/diferenciações entre o lugar de uma classe/fração no âmbito das práticas políticas e da cena política. Isso significa dizer que uma fração pode deter a hegemonia restrita (ao bloco no poder) - a fração politicamente dominante -, mas pode não estar representada de forma orgânica por nenhum partido no sistema político, que é dominado pelas frações reinantes - que são aquelas que mantêm partidos políticos nos lugares dominantes da cena política -, nem, tampouco, constitui-se na fração detentora do aparelho de Estado. Esta última é aquela fração que recruta os políticos, os burocratas e os militares das diversas frações de classe, inclusive em algumas situações nos segmentos dominados, para ocupar cargos nos diversos órgãos do Estado.

Essas três dimensões ou lugares concreto-históricas (fração hegemônica no interior do bloco no poder; fração reinante; fração detentora) podem assumir va-

\footnotetext{
${ }^{10}$ Poulantzas (1985, p. 38) destacou que "a relação das massas com o poder e o Estado, no que se chama especialmente de consenso, possui sempre um substrato material. Entre outros motivos, porque o Estado, trabalhando para a hegemonia [ampla] de classe, age no campo do equilíbrio instável do compromisso entre as classes dominantes e dominadas. Assim, o Estado encarrega-se ininterruptamente de uma série de medidas materiais positivas para as massas populares, mesmo quando estas medidas refletem concessões impostas pela luta das classes dominadas”.
} 
riadas combinações e, até mesmo, pode ocorrer uma situação em que a fração de classe pode ser reinante e detentora sem necessariamente fazer parte do bloco no poder. Assim, tendo em vista as três dimensões ou lugares que permeiam as relações entre estas instâncias, é preciso identificar as diferenças entre práticas e cenas políticas. Nesse contexto, o bloco no poder, e a relação entre suas frações internas, se apresenta como um instrumento fundamental para localizar e decifrar a significação real das práticas políticas de classe, bem como (i) suas relações com os partidos que operam na cena política e (ii) suas relações com a fração política detentora do aparelho de Estado.

É preciso acentuar ainda que as práticas políticas, portanto, só conseguem ser percebidas por meio da análise da dinâmica do bloco no poder em seus espaços concretos de atuação. Ou seja, o bloco no poder não deve ser utilizado apenas num nível mais elevado de abstração, mas sim como uma categoria analítica (concreto-real) útil para a observação da conjuntura econômica e política da luta de classes, que se materializa no locus da luta política de classes, o Estado, e está eminentemente articulada com o locus da luta econômica de classe e de suas frações.

A partir dessa interconexão (locus do econômico e do político), o Estado não é definido aqui por meio de ideias préconcebidas a respeito do seu papel ativo ou passivo, muito menos é concebido como uma derivação. Na verdade, numa perspectiva relacional, ${ }^{11}$ considera-se que o Estado é a combinação (em maior ou menor grau) desses dois eixos (autonomia da administração central x subordinação do Estado a determinados interesses), a qual é determinada por uma dada conjuntura espacial e temporal. Oliveira (2004, p. 334, grifo nosso) deixa mais claro esse tipo de análise da mediação entre sociedade civil e Estado:

A relação entre Estado e sociedade em formações socioeconômicas requer algo mais que a simples confrontação entre criador e criatura, qual seja, quem faz emergir quem. [...] As recíprocas influências não permitem simplificações analíticas ou subestimações de papéis, muito menos afirmações de soberania de instâncias como as estatais. Mais importante é desvendar como os elementos de um perfil estatal vão se delineando no próprio modelo organizativo da sociedade [...]

Para Poulantzas (1985) e Codato e Perissinotto (2001), as obras históricas de Marx, em seu conjunto, não apresentavam o determinismo de classe como pressuposto, tampouco a sobredeterminação do Estado. Na verdade, estas obras sinalizam o tipo de mediação entre a sociedade civil e o Estado por intermédio da qual o papel reprodutivo do Estado aparece tanto num (i) nível abstrato-formal ("teoria geral do modo de produção capitalista" - como visto na seção anterior) quanto num (ii)

\footnotetext{
11 "Entender o Estado como condensação material de uma relação de força [perspectiva relacional], significa entendê-lo como um campo e um processo estratégico, onde se entrecruzam núcleos e redes de poder que ao mesmo tempo se articulam e apresentam contradições uns em relação aos outros [...]" (Poulantzas, 1985, p. 157).
} 
nível concreto-real. Neste nível mais reduzido de abstração, a análise do papel do Estado deve levar em conta a possibilidade de separação entre "poder de Estado" e "poder de classe", uma vez que nesta dimensão o Estado é o locus em que se configuram "as lutas políticas de grupos, de facções e de frações de classe". Com isso, o Estado acaba assumindo capacidade de decisão e de iniciativa relativas diante das frações do bloco no poder (Codato \& Perissinotto, 2001, p. 17), podendo inclusive vir a ser mais influenciado, em certo grau, por segmentos que estão colocados fora do mesmo. Isso não significa dizer que o Estado deixa de ser o espaço de dominação do bloco no poder, mas sim que em determinadas conjunturas históricas e espaciais o Estado é mais ou menos permeável a certas demandas dos segmentos fora do bloco, mais especificamente dos segmentos dominados. Na verdade,

[...] as lutas populares atravessam o Estado de lado a lado, e isso não acontece porque uma entidade intrínseca penetra-o do exterior. Se as lutas políticas que correm no Estado atravessam seus aparelhos, é porque essas lutas estão desde já inscritas na trama do Estado do qual elas esboçam a configuração estratégica. Certamente, as lutas populares, e mais geralmente os poderes, ultrapassam de longe o Estado: mas por mais que elas sejam (e elas são) propriamente políticas, não lhe são realmente exteriores. Rigorosamente falando, se as lutas populares estão inscritas no Estado, não é porque sejam absorvidas por uma inclusão num Estado totalizante, mas sim antes porque é o Estado que está imerso nas lutas que o submergem constantemente. Fica entendido no entanto que até as lutas (e não apenas as de classe) que extrapolam o Estado não estão no entanto "fora do poder", mas sempre inscritas nos aparelhos de poder que as materializam e que, também eles, condensam uma relação de forças (as fábricas-empresas [grupos econômicos], a família numa certa medida etc.). (Poulantzas, 1985, p. 162, grifo do autor)

Sendo assim, é possível pensar o "poder de Estado" separado do "poder de classe" destacando que estes dois poderes estão numa constante relação conflituosa quando apreendido no nível "concreto-real". Desse modo, o Estado, nessa dimensão, é o espaço de conflito das frações do bloco no poder que tem, geralmente, como objetivos manter ou ampliar, ao mesmo tempo, a sua fatia da renda e da riqueza e sua participação no âmbito político e ideológico (autoridade, influência e legitimidade) (Gonçalves, 2005). Além dessa disputa no interior do bloco no poder, o Estado, nesse nível analítico, ainda é atravessado em seus aparelhos pelas lutas populares.

Dado esse amplo leque de disputas e interesses, as políticas de Estado, no curto prazo, aparece como o resultado das relações de forças no seio do Estado; ou seja, as políticas refletem "processos extremamente contraditórios, de medidas, de contramedidas, de blocagens, de filtragens escalonadas" (Poulantzas, 1985, pp. 96-97). Caso olhássemos apenas o funcionamento do Estado, no nível concreto-real, concluiríamos que suas políticas e resultados são extremamente caóticos e contraditó- 
rios. Todavia, ao se juntar a observação do bloco no poder (observação do concreto-real) com o capital em geral, verifica-se que os resultados das políticas são a manifestação da hegemonia restrita (ou ampliada) do bloco no poder que leva à ampliação da acumulação capitalista de forma geral e em maior grau a da fração hegemônica.

Poulantzas, em sua última obra (O Estado, o poder e o socialismo), ao reformular as suas primeiras análises acerca do Estado capitalista enfatizando as lutas de classe, tenta "fugir" da análise parcial dos seus primeiros trabalhos (em especial Poder político e classes sociais) que carregavam consideráveis influências estruturalistas. ${ }^{12}$ A partir desta reformulação, Poulantzas (1985) defende que o Estado pode assumir, ao mesmo tempo, o papel de produtor e modelador das relações objetivas, numa dada conjuntura específica, na medida em que funciona como o principal locus da luta política de classes.

Ao analisar a sociedade capitalista, Poulantzas (1985) observa que, dada a separação entre as estruturas econômicas e o Estado, decorrente do isolamento e da desapropriação dos produtores diretos dos seus meios de produção, fez-se necessário promover a ideologia capitalista que apregoa a igualdade dos indivíduos na vida política como elemento de manutenção do status quo. Fixadas as desigualdades das relações econômicas com a maior concentração e centralização de capital, a ideologia capitalista alçou o conceito de democracia formal, no nível político, como précondição necessária do capitalismo, já que nessa dimensão, incluindo o aparelho jurídico, todos os membros da sociedade são iguais (uma cabeça um voto).

Neste contexto, o Estado “deve 'parecer' autônomo e neutro, enquanto ao mesmo tempo, mantém as classes dominadas divididas e representa os interesses do bloco no poder das classes dominantes" (Poulantzas, 1985). Poulantzas deixa evidente que o Estado tornou-se o objeto de luta a partir do deslocamento da luta econômica de classe para o locus político, ainda mais quando se sabe que, com sua autonomia relativa, o Estado possui (poder de Estado separado do Poder de classe) a capacidade de garantir a representação de classe e a organização da hegemonia restrita ou ampla. ${ }^{13}$

O Estado, nesta perspectiva, não deve ser compreendido como uma entidade monolítica, tampouco menos homogênea, já que se funda num sistema institucional de aparelhos diferentes, em outras palavras, num sistema estatal ${ }^{14}$ que apresenta

12 Para Carnoy (1986) e Coutinho (2007), a reformulação teórica de Poulantzas distanciou-o da influência estruturalista de Althusser, ao mesmo tempo em que o aproximou das ideias de Gramsci.

${ }^{13}$ Para Coutinho (2007, p. 187), Poulantzas ao adotar tal compreensão do Estado capitalista "superou dialeticamente Gramsci", na medida em que ele amplia "a luta pela hegemonia e pela conquista de posições" além da sociedade civil (aparelhos privados de hegemonia) como tivera feito Gramsci, incorporando também nessa luta pela hegemonia os "aparelhos estatais em sentido restrito (no que Gramsci chamou de 'sociedade política')".

${ }^{14}$ Adota-se aqui o conceito apresentado por Codato (1997, pp. 36-37), a saber: "Entendo por 'sistema estatal' [...] o conjunto de instituições públicas e suas ramificações específicas (funcionais, setoriais e espaciais) encarregadas da administração quotidiana dos assuntos de governo. Utilizo essa noção aqui 
níveis de poder diferentes. Os aparelhos que concentram a capacidade de decidir ("poder efetivo") são os "centros de poder" do Estado. Na verdade, eles são o locus institucional onde as decisões fundamentais são efetivamente tomadas, inclusive sem nenhuma subordinação hierárquica a outra agência burocrática do sistema estatal. Consequentemente, estes são os locais institucionais do Estado para onde são direcionadas as principais demandas das classes ou frações de classes dominantes (Codato, 1997).

É preciso destacar que os centros de poder do sistema estatal podem se modificar ao longo do tempo, bem como podem assumir uma maior ou menor autonomia relativa perante algumas frações das classes dominantes, numa dada conjuntura histórica, pois o seu poder não emana do fato de possuir uma força própria distinta do poder de classe (ao estilo weberiano ${ }^{15}$ ), mas sim da sua relação no âmbito da luta de classe. Neste contexto, o predomínio político (práticas políticas) de uma dada fração de classe é fruto "do controle ou influência que essa classe (ou seus representantes) pode exercer sobre o aparelho que concentra o poder efetivo" (Codato \& Perissinoto, 2001, p. 23).

Cabe, aqui, realizar novamente uma rápida digressão a respeito das diferentes dimensões da prática e da cena política para que possamos explicar o sistema institucional do Estado e seus desenlaces com o bloco no poder. Quando o representante de uma determinada fração de classe assume os "centros de poder" do Estado não significa dizer necessariamente que essa fração tornou-se uma fração detentora, mas sim que ela, quase sempre, é a fração hegemônica no interior do bloco no poder. A ocorrência deste fato demonstra que as frações dominantes conseguiram impor suas estratégias e objetivos mesmo sem a necessidade de se transformar em uma classe detentora. Em outras palavras, para que uma classe ou fração - seja ela dominante ou dominada - consiga controlar os centros de poder do Estado é preciso muito mais do que uma "simples" vitória eleitoral.

Poulantzas (1985, p. 159) deixa isso muito claro:

Mesmo no caso em que a esquerda no poder, além de ocupar o governo, controle realmente os setores e aparelhos de Estado, nem por isso ela controla forçosamente aqueles, ou um entre eles, que detém o papel dominante no Estado, que constituem o pivô central do poder real [centro de poder]. A unidade centralizada do Estado não reside numa pirâmide na qual bastaria ocupar o cume para garantir seu controle.

de forma descritiva, pois não pretendo sugerir que as agências do Estado possuam uma integração perfeita entre si ou uma articulação 'racional' segundo uma lógica burocrática abstrata [...]. [Nesse contexto, fazem] parte do 'sistema estatal' as cúpulas do Executivo (o 'governo' propriamente tido), a administração civil (ou 'burocracia'), o judiciário, as assembléias parlamentares, os governos locais e o aparelho repressivo (forças armadas e polícia)".

${ }^{15}$ Para uma perspectiva weberiana/gerencial sobre a discussão do Estado e da política ver Bresser-Pereira (2010) e Bresser-Pereira (2001). 
Caso essa classe ou fração detentora (na cena política) de esquerda realmente deseje controlar os centros de poder, faz-se necessário estabelecer mudanças estruturais que reverberem em práticas políticas da luta de classe, bem como incidam no lugar de exploração que a fração hegemônica exerce no processo produtivo. Isto significa necessariamente mudar as coalizões de forças sociais, isto é, mudar a composição e a estrutura do bloco no poder e fora dela. Situação esta que, quase sempre, pode gerar fortes tensões institucionais (crises políticas).

Deste modo, as políticas estatais tendem a expressar, por sua vez, os movimentos contraditórios que se desenvolvem no aparelho de estado e que são fruto de determinada conjuntura das forças sociais no bloco no poder. A política pública, em especial a econômica, portanto, não pode ser apreendida apenas pela ideia de que ela é configurada como um desenho de especialistas ou como um campo neutro, destituído, à moda positivista, de qualquer juízo de valor. $\mathrm{Na}$ verdade, o enfoque defendido aqui é que a política pública, mesmo parecendo caótica e contraditória no curto prazo, é originaria da interação e dos conflitos de um processo decisório que expressa, no longo prazo (aqui entendido como equivalente ao nível abstrato-formal), um interesse hegemônico da fração dominante no bloco no poder (Oliveira, 2004).

Desse modo, a intervenção estatal (políticas públicas) é o reflexo da correlação de forças políticas das frações do bloco no poder em momentos históricos e espaciais determinados, bem como da maior ou menor autonomia relativa dos centros de poder do Estado capitalista.

Até aqui desconsideramos os condicionantes externos para a dinâmica do bloco no poder. Porém, trataremos de quebrar esse suposto, pois os movimentos internos (bloco no poder e intervenção estatal) quase sempre também sofrem forte influência das condições internacionais, que necessariamente dependem da posição, central ou periférica, ocupada por um determinado Estado na hierarquia do sistema internacional.

\section{O ESTADO E O SISTEMA INTERNACIONAL: PROJEÇÃO DO PODER DE CLASSE (BLOCO NO PODER) PARA ALÉM DOS SEUS ESPAÇOS NACIONAIS}

As relações entre os Estados são delineadas a partir da posição hierárquica em que cada um deles se coloca no sistema internacional. Em outras palavras, depende do grau de acumulação de capital de cada nação e também do conteúdo e da dinâmica do bloco no poder que lhe é inerente Consequentemente, o posicionamento de "comando" de um determinado país depende da configuração intraestatal das forças produtivas, da divisão do trabalho e do intercâmbio internos. A propósito, Marx e Engels, em passagem do livro A ideologia alemã, alertaram para os impactos das características de uma determinada formação social, tendo em vista suas dimensões internas e externas, sobre suas relações com outras nações:

As relações entre umas nações e outras dependem do estado de desenvolvimento em que se encontra cada uma delas no que concerne às 
forças produtivas, à divisão do trabalho e ao intercâmbio interno. Tal princípio é em geral conhecido. Entretanto, não apenas a relação de uma nação com outras, mas também toda estrutura interna desta mesma nação, dependem do grau de desenvolvimento de sua produção e de seu intercâmbio interno e externo [...]. (Marx \& Engels, 1846, pp. 28-29)

Ainda que tivessem indicado pistas para o entendimento das relações entre as nações e terem destacado o processo de internacionalização do regime de produção burguesa, Marx e Engels não avançaram em seus estudos a respeito das relações entre os países, assim como pouco trataram da questão da hierarquia no sistema internacional moderno, o qual, pode-se dizer, foi consolidado após a Paz de Westfália em 1648. Mas, sendo a hierarquia um traço decisivo na composição deste sistema, nunca é demais lembrar que o mesmo sempre foi, e continua sendo, marcado historicamente por conflitos interestatais e por um processo desigual de desenvolvimento capitalista. ${ }^{16} \mathrm{~A}$ depender da posição de um determinado Estado na hierarquia do sistema, ele pode exercer sua soberania, num maior ou menor grau, diante dos outros Estados mediante o uso da força (guerra ou preparação para a guerra) e/ou por meio da atuação direta e indireta nas organizações internacionais (ONU, FMI, Banco Mundial, OMC etc.).

Particularmente, ao aplicarem os conceitos de economia-mundo e sistema-mundo, Braudel (1987) e Wallerstein (1985) estão entre os autores que melhor abordaram o fenômeno da hierarquização no âmbito do sistema internacional moderno. Para Braudel (1987), a economia-mundo pode ser definida, em primeiro lugar, por se constituir como um determinado espaço geográfico, cujos limites podem variar no tempo, e, em segundo lugar, por apresentar um centro e uma periferia dependente, principalmente no âmbito comercial. Por outro lado, segundo Wallerstein (1985), o sistema-mundo corresponde a uma estrutura social delimitada por fronteiras e grupos integrantes que, ao mesmo tempo, desfruta de legitimidade social. Nele estão presentes forças, as quais, embora conflituosas, o sustentam como um sistema unido através da tensão gerada internamente, já que o mesmo apresenta uma dinâmica histórica gradual no que diz respeito à ascensão de determinados grupos sociais (capitalistas comerciais, produtivos e financeiros). Logo, a dinâmica do sistema-mundo torna-se possível por intermédio da construção hierárquica, à imagem e semelhança de uma sociedade capitalista. Então, resumidamente, as três características do sistema-mundo são as seguintes: i) trata-se de um sistema econômico integrado mundialmente de forma polarizadora a partir do centro do sistema; ii) apresenta-se como um sistema político baseado em outros sistemas soberanos relacionados, mas com relações hierarquias bem definidas entre

\footnotetext{
16 “O sistema internacional é, na sua essência, um sistema dinâmico que envolve poder e, portanto, é um sistema de conflito permanente (aberto ou oculto) e equilíbrio instável. Assim, no sistema internacional, a guerra e a paz, a harmonia e o conflito não são fins em si mesmos e, sim, meios de se alcançarem objetivos específicos nos campos econômico, político, cultural e militar. Nesse sistema dinâmico, relações e processos provocam mudanças nas estruturas” (Gonçalves, 2005, p. 13).
} 
os mesmos; e iii) contém um modelo cultural que confere legitimidade e coerência ao sistema.

Contudo, o debate a respeito do caráter hierarquizado do sistema internacional moderno foi precedido pela contribuição dos teóricos marxistas do imperialismo. Dentre eles, destacam-se Hilferding, Bukharin e Lênin, que levantaram questões importantes para a apreensão das interconexões da dinâmica interna da acumulação e das disputas entre as classes, sem, contudo, adotarem explicitamente o conceito de bloco no poder. Ademais, outra questão de relevância tratada pelos teóricos marxistas do imperialismo alude ao movimento externo ao Estado, o que remete ao papel de comando do estado nacional no interior do sistema internacional.

Nesse sentido, vejamos algumas destas questões. Hilferding (1910) introduz uma importante contribuição ao desenvolvimento da teoria econômica marxista quando formula o conceito do capital financeiro. Afirma, portanto, que os fenômenos da concentração e da centralização do capital estão na origem da transformação da estrutura da dinâmica da acumulação, ocorrida entre o final do século XIX e início do século XX, principalmente nos países centrais da Europa, mediante a interpenetração entre o capital industrial e as instituições bancárias por intermédio das sociedades por ações. Logo, o capital financeiro, uma estrutura totalizante, corresponde a um processo de "fusão" entre banco (grande burguesia bancária) e indústria (grande burguesia industrial), de tal forma a possibilitar a constituição de uma nova forma de fração de capital.

Nesse sentido, o capital financeiro constitui-se numa categoria histórico-institucional datada, ou seja, numa fração dominante numa determinada conjuntura da luta de classes que tinha como objetivo primordial manter e ampliar as suas taxas de lucros (mais-valia). Para tanto, adotou, segundo Hilferding (1910), uma estratégia que articulava três objetivos, a saber: i) a criação de um território econômico tão vasto quanto possível; ii) a defesa desse território por meio de barreiras aduaneiras; e iii) a transformação desse território em espaço de exploração para monopólios do seu país.

O avanço desse capital financeiro a partir do final do século XIX gerou, progressivamente, a concentração da produção, fenômeno que se expressou por meio da constituição de um reduzido número de grandes associações capitalistas, da separação entre a propriedade das empresas e a direção das mesmas e da socialização máxima da produção dentro da lógica capitalista. Além disso, criou também uma nova relação entre a dinâmica dos sistemas de monopólios e os conflitos inter-estatais. Segundo Hilferding (1910), Lênin (1916) e Bukharin (1918), com o avanço dos monopólios e dos cartéis, fez-se necessário retomar e ampliar o protecionismo, tendo em vista a redução ou a eliminação da concorrência estrangeira no mercado interno. No contexto de menor concorrência capitalista interna, a elevação dos preços dos monopólios tende a provocar uma redução das vendas internas, o que justifica a realização no exterior de parte da produção interna. Assim, as exportações tornam-se cada vez mais importantes para a manutenção e ampliação da produção em grande escala das principais economias capitalistas.

Mas, no que diz respeito aos vínculos com o mercado mundial, a lógica do 
capital financeiro tem na necessidade de exportação de mercadorias uma variável apenas secundária, posto que a exportação de capital passa a ser o objetivo mais importante entre os interesses das nações capitalistas adiantadas. A ampliação da área de influência nas regiões econômicas sob seu domínio possibilita ao capital financeiro a ampliação da escala de produção dos países centrais em espaços nacionais periféricos, nos quais o valor da força de trabalho é mais baixo, o que contribui para a manutenção das taxas de lucro mais elevadas dos monopólios. Tal dinâmica requer, necessariamente, uma forte política expansionista que só poderia ser alcançada por meio do apoio e da intervenção ativa do Estado. Intervenção esta direcionada à aquisição e à manutenção do controle sobre novas áreas econômicas, em outras palavras, fez-se necessário políticas nacionais expansionistas. Isso, por sua vez, gera uma intensificação do conflito entre os maiores Estados capitalistas, pois cada um deles terá como objetivo ampliar cada vez mais suas áreas de influência e/ou controle de territórios socioeconômicos.

Isto posto, podemos passar a polemizar a questão da relação entre o Estado e o sistema internacional implícita ao modelo de Hilferding. Para tanto, lançaremos mão das contribuições de José Luis Fiori, um estudioso brasileiro que tem se destacado no exame das relações econômicas e políticas internacionais. Fiori avalia que o modelo de Rudolf Hilferding poderia ser considerado como uma reelaboração do argumento de Marx na medida em que desloca o método analítico do "capital em geral" para introduzir em seu lugar o "Estado nacional" como ponto de partida. Hilferding teria trazido "os estado nacionais e suas guerras para dentro de sua teoria do desenvolvimento capitalista do capital monopolista e financeiro" e, com isso, teria conseguido compreender a dinâmica de expansão e competição do sistema mundial. Entretanto, segundo Fiori, a questão da dinâmica expansiva do sistema é um tema controverso presente nesta formulação, já que os teóricos do imperialismo descrevem a expansão como uma fase particular do capitalismo, quando, na verdade, seria uma característica sempre presente no sistema internacional moderno (Fiori, 2004, p. 43).

Nessa linha, Fiori (2004 e 2007) argumenta que os teóricos do imperialismo, ao adotarem como ponto de partida metodológico o Estado nacional, deixam claro que a expansão do sistema capitalista não teria sido obra do "capital em geral”, conforme Marx teria concluído, mas, sim, teria acontecido como consequência da expansão e da competição dos estados e economias nacionais "que conseguem impor sua moeda, a sua 'dívida pública', o seu sistema de crédito e os seus sistemas de tributação, como lastros monetários do seu capital financeiro dentro destes territórios econômicos supranacionais e em expansão contínua" (Fiori, 2004, p. 46).

Todavia, alternativamente, é possível afirmar que a expansão do sistema capitalista, em seus rebatimentos para as formações sociais historicamente determinadas, realmente não decorreu do "capital em geral", nem, muito menos, pode ser atribuída a uma racionalidade estatal (ao estilo weberiano, em que o Estado emerge como um criador racional gerando as condições para a criação de um mercado interno) como afirma Fiori $(2004,2007,2008)$, mas, de fato, adveio da dinâmica 
dos diversos blocos no poder que projetaram suas forças, por intermédio dos seus Estados, além dos seus espaços nacionais, mais especificamente na arena das disputas do sistema internacional moderno.

Ainda quanto à análise do sistema internacional moderno realizada por Fiori $(2004,2007,2008)$ podemos destacar dois elementos importantes para a compreensão da questão da hierarquia, a saber, a moeda e as armas. No que se refere ao primeiro item, aquele autor advoga que o Estado que lidera a acumulação de capital é aquele que consegue impor sua unidade monetária como a moeda de curso internacional, permitindo assim que sua dívida pública e seu sistema de crédito funcionem como lastros monetários para a expansão de suas frações do capital (bloco no poder) para além dos seus espaços territoriais. No que tange às armas (guerra e a preparação para a guerra), argumenta que elas funcionam como instrumentos tanto de conquista e acúmulo de poder como de defesa e preservação. Portanto, quanto mais elevado o grau de soberania de um Estado, dado que sua moeda é a de curso internacional e suas forças armadas apresentam grande superioridade, maior é a capacidade do seu bloco no poder (termo não utilizado por Fiori) em expandir seus espaços de acumulação além de suas fronteiras.

Embora destaque questões muito relevantes, em nossa opinião a modalidade de interpretação tal como a exposta por Fiori tem um poder de explicação limitado porque deixa de lado outras dimensões relevantes. Uma delas é a questão da mediação entre o Estado e a dinâmica interna do bloco no poder. Pensamos que, ao tentar fugir de uma mediação economicista entre o Estado e as classes sociais, Fiori (2004) acabou caindo em outro extremo ao adotar uma postura politicista. Nesta o Estado surge como um criador - numa combinação entre a visão hegeliana e weberiana descolado das bases materiais, econômicas e ideológicas, da sociedade e possui uma racionalidade política e econômica acima dos segmentos da sociedade.

Tendo isso em vista, é preciso destacar que as armas e a moeda explicam apenas uma parte da questão do poder no sistema internacional moderno. Por isso, faz-se necessário incorporar também a questão da mediação entre o Estado e as frações de classe por meio da noção de bloco no poder, conforme visto na terceira seção, que traz em si elementos políticos e econômicos de forma articulada. Esta é a noção mais adequada a ser empregada no que diz respeito ao papel do Estado relativamente àquela mediação, já que permite efetivamente neutralizar as formulações economicistas e politicistas mencionadas anteriormente; como também permite a inclusão do papel das arenas internacionais (organizações internacionais) onde a estratégia do convencimento é utilizada como uma arma poderosa para o Estado dominante e suas frações de classe.

Além do emprego da força, a manutenção da hierarquia no sistema internacional moderno é mantida também mediante a mobilização das organizações internacionais (ONU, FMI, Banco Mundial, OMC etc.) que cumprem pelo menos dois papéis fundamentais no jogo político internacional, a saber: i) atuam como arenas políticas regulatórias onde são corporificadas as regras internacionais que facilitam a expansão das forças econômicas e sociais dominantes, pois, segundo Cox (2007), geralmente as regras adotadas tem origem no Estado dominante, em- 
bora também tenham que ser apoiadas por outros Estados; e ii) legitimam ideologicamente as regras e valores culturais da ordem internacional, que se originam do Estado (e de seu bloco no poder) mais poderoso, por meio da definição de diretrizes e práticas políticas para outros diversos Estados nacionais.

\section{CONCLUSÕES}

Procurou-se ao longo deste trabalho realizar uma teorização do Estado apoiada em Poulantzas e orientada mediante uma diretriz metodológica aqui denominada de perspectiva relacional. Nesse sentido, buscou-se identificar o papel desempenhado pelo Estado tanto da dimensão abstrato-formal, que corresponde à importante dimensão da acumulação de capital, como no plano concreto-real, que se situa como o locus das disputas políticas do bloco no poder e dos segmentos populares e como espaço central nas disputas por poder na arena do sistema internacional moderno.

Preliminarmente, colocou-se em relevo as limitações de algumas importantes abordagens do papel do Estado no modo de produção capitalista, sobretudo as chamadas correntes estruturalista, classista e derivacionista. O núcleo central dessas abordagens repousa sobre a acumulação no plano abstrato formal (do capital em geral), pressuposto que limita demasiadamente o poder explicativo da função e atuação estatal pró-capital, conquanto deixa de lado a dimensão concreto-real. Assim, como aqui se enfatizou, os fenômenos que se manifestam na conjuntura, espaço incontornável de disputa entre as diversas frações de classe, correspondem a um complexo cenário que necessariamente deve ser incorporado à estrutura analítica que pretende caracterizar as funções estatais acima aludidas. Afirmativamente, apontou-se que as análises do Estado que se apegam apenas ao plano abstrato formal, não conseguem apreender a conjuntura dos conflitos políticos que são travados no interior do Estado.

Considerando-se o conteúdo da conclusão acima descrita, a seguir, convém destacar outra importante argumentação decorrente da utilização do procedimento de integração da dimensão abstrato-formal com a dimensão concreto-real. Diz respeito, por conseguinte, à correta assimilação das políticas estatais, notadamente a econômica. Diferentemente de muitas formulações teóricas, de extração conservadora ou mesmo algumas que se posicionam no campo da crítica ao capitalismo, conclui-se que as políticas estatais (políticas públicas ou políticas econômicas) de maneira alguma possuem um conteúdo neutro. $\mathrm{Na}$ verdade, elas expressam, no curto prazo, os movimentos conflitantes do bloco no poder que se desenvolvem no interior do Estado. Muito embora esses movimentos muitas vezes pareçam caóticos, no entanto, no longo prazo, é possível enxergar o interesse hegemônico da fração dominante no bloco no poder que necessariamente persegue o objetivo primordial de ampliação da acumulação do capital como um todo.

Finalmente, chamamos a atenção para os desdobramentos da aplicação do conceito de bloco do poder no plano das relações entre Estados na esfera do siste- 
ma internacional moderno. Nesse sentido, partiu-se de um modelo clássico do pensamento marxista atinente à interpretação das mudanças estruturais do capitalismo. Vimos, então, que a formulação do capital financeiro, elaborada por Hilferding, permite vislumbrar a apreensão das transformações do capitalismo em determinado período de seu desenvolvimento, já que, a nosso juízo, contém implicitamente, alguns elementos analíticos equivalente a certas categorias do conceito de bloco no poder. O modelo de Hilferding, embora escorado no pressuposto do capital em geral, também enfatiza a existência de uma ordem internacional hierarquizada entre os Estado-nações, ordem esta igualmente reconhecida nas abordagens do sistema-mundo, em que se destacam Braudel e Wallerstein.

A economia capitalista mundializada apresenta como uma de suas normas principais a procura permanente da expansão da dominação do bloco no poder dos países capitalistas centrais para além dos seus espaços nacionais. Todavia, Fiori, um dos autores brasileiros mais importantes na formulação de abordagens teóricas acerca das relações estatais internacionais, apresenta opinião divergente ao afirmar que, ao contrário, Hilferding teria invertido a justificativa originária de Marx para a expansão internacional do capitalismo, o capital em geral, para colocar em seu lugar a competição entre estados e economias nacionais. Ao fazê-lo desse modo, Fiori, infelizmente, acaba por atribuir demasiada importância a uma suposta "racionalidade estatal", perdendo de vista, portanto, a ação decisiva das frações de classes que compõem os blocos no poder para a efetivação do característico cenário hierarquizado da economia mundial, ou do sistema internacional de Estado-nações.

\section{REFERÊNCIAS BIBLIOGRÁFICAS}

BONEFELD, W. (1987) “Reformulation of State Theory”, Capital \& Class, n. . 33, pp. 96-127.

BRAUDEL, F. (1987) A dinâmica do capitalismo. Rio de Janeiro: Rocco.

BRESSER-PEREIRA, L. C. (2001) “Do Estado Patrimonial ao gerencial”. In: PINHEIRO \& WILHEIM, J. \& SACHS, I. Brasil: um século de transformação. São Paulo: Companhia das Letras.

BRESSER-PEREIRA, L. C. (2010) “A construção política do Estado”. Lua Nova, São Paulo, no 81, pp. 117-146.

BRUNHOFF, S. (1985) Estado e capital. Uma análise da política econômica. Rio de Janeiro: Forense Universitária.

BUKHARIN, N. (1918 [1986]) A economia mundial e o imperialismo. São Paulo: Nova Cultura.

CARDOSO Jr., J. \& PINTO, E. \& LINHARES, P. (2010) “O Estado brasileiro e o Desenvolvimento Nacional”. In: PINTO, E. \& CARDOSO Jr., J. \& LINHARES, P. (Org.) Estado, Instituições e Democracia: Desenvolvimento. Brasília: IPEA, v. 3, pp. 17-50.

CARNOY, M. (1986) Estado e teoria política. Campinas/SP: Papirus.

CODATO, A. N. \& PERISSINOTTO, R. M. (2001) "O estado como instituição. Uma leitura das obras históricas de Marx”, Crítica Marxista, n. ${ }^{\circ}$ 13, Editora Revan, pp. 9-28.

CODATO, A. N. (1997) Sistema Estatal e Política Econômica no Brasil pós-64. São Paulo: Editora Hucitec.

COUTINHO, C. (2007) Gramsci: um estudo sobre seu pensamento político. Rio de Janeiro: Civilização Brasileira.

COX, R. (2007) “Gramsci, hegemonia e relações internacionais: um ensaio sobre método”. In: GILL, S. 
Gramsci: materialismo histórico e relações internacionais. Rio de Janeiro: Editora UFRJ, pp. 101124.

FIORI, J. L. (2004) "Formação, expansão e limites do poder global”. In: FIORI, J. L. (Org.) O poder americano. Petrópolis/RJ: Vozes, pp. 11-64.

FIORI, L. (2007) O poder global. São Paulo: Boitempo.

FIORI, L. (2008) "O sistema interestatal capitalista no início do século XXI". In: FIORI, J. \& MEDEIROS, C. \& SERRANO, F. (Org.) O Mito do Colapso do Poder Americano. Rio de Janeiro: Record, pp. 173-277.

GONÇALVES, R. (2005) Economia politica internacional: fundamentos teóricos e as relações internacionais do Brasil. Rio de Janeiro: Elsevier.

GRAMSCI, A. (1949 [1978]) Maquiavel, a política e o Estado moderno. Rio de Janeiro: Civilização Brasileira.

HILFERDING, R. (1910 [1985]) O capital financeiro. São Paulo: Nova Cultural.

LENIN, W. I. (1916 [1979]) Imperialismo, fase superior do capitalismo. São Paulo: Global.

MARX, K. \& ENGELS, F. (1846 [1999]) A ideologia alemã (I - Feuerbach). São Paulo/SP: Editora Hucitec.

MARX, K. \& ENGELS, F. (1848 [1998]) “Manifesto do Partido Comunista”. In REIS FILHO, Daniel Aarão (Org.). O manifesto comunista 150 anos depois. Rio de Janeiro/Contraponto, São Paulo/ Fundação Perseu Abramo.

MARX, K. (1852 [2002]) O 18 Brumário e Cartas a Kugelmann. Rio de Janeiro: Paz e Terra.

MARX, K. (1867 [1986]) O capital: crítica da economia política. São Paulo: Nova Cultural (Os Economistas).

MARX, K. (1850 [1986]) As lutas de classes na França (1848-1850). São Paulo: Global.

MILIBAND, R. (1970) O Estado na sociedade capitalista. Rio de Janeiro: Zahar.

MOLLO, M. R. (2001) “A concepção marxista de Estado: considerações sobre antigos debates com novas perspectivas", Revista Economia (ANPEC), v. 2, nº 2, jul-dez, Editora Komedi.

OLIVEIRA, N. (2004) Neocorporativismo e politica pública: um estudo das novas configurações assumidas pelo Estado. São Paulo: Edições Loyola/CEAS.

PANITCH, L. \& GINDIN, S. (2005) “Superintending Global capital”, New left review, n 35, Sept/Oct.

PINTO, E. (2010) Bloco no poder e Governo Lula: grupos econômicos, política econômica e novo eixo sino-americano. Tese (Doutorado) - Instituto de Economia, Universidade Federal do Rio de Janeiro.

POULANTZAS, N. (1982) “O Estado, o poder e nós”. In: BALILAR, E. \& POULANTZAS, N. (Org.) O Estado em discussão. Lisboa: Edições 70.

POULANTZAS, N. (1985) O Estado, o poder, o socialismo. Rio de Janeiro/RJ: Graal.

POULANTZAS, N. (1977) Poder político e classes sociais. São Paulo: Martins Fontes.

WALLERSTEIN, I. (1985) O capitalismo histórico. São Paulo: Brasiliense. 